\title{
The Effect of Teacher Training on the Knowledge of Positive Behavior Support and the Quality of Behavior Intervention Plans: A Preliminary Study in Taiwan
}

\author{
Running Head: Positive Behavior Support
}

\author{
Pei-Fang Wu \\ Department of Special Education, National Kaohsiung Normal University, Taiwan
}

Copyright $\bigcirc 2017$ by authors, all rights reserved. Authors agree that this article remains permanently open access under the terms of the Creative Commons Attribution License 4.0 International License

\begin{abstract}
The purpose of this study was to investigate whether through a series of teacher training. The participants could acquire better knowledge on Positive Behavior Support (PBS), and develop high quality behavior intervention plans. Thirty-six teachers from three public schools participated in the study. The competency-based training consisted of 12 sessions based on several key concepts of PBS. The participants were divided into 7 groups, and each group was required to complete a section of behavior intervention plan after each training session, until all sections were completed. A group pretest-training-posttest pre-experimental design was used to compare the knowledge and the quality of behavior intervention plans before and after the training. Results showed the knowledge of PBS and the substantive quality of PBS plans can be improved with teacher training. The implications for future research and practices were discussed.
\end{abstract}

Keywords Behavior Intervention Plan, Positive Behavior Support, Teacher Training

\section{Introduction}

The implementation of positive behavior support (PBS) and the use of functional behavior assessments are mandated in special education laws in the United States, to address behavioral needs for students with disabilities. The Individuals with Disabilities Education Act (IDEA) of 2004 requires the Individualized Education Plan (IEP) team to consider the use of PBS and conduct functional behavior assessments on students with behavioral problems. In Taiwan, the Enforcement Rules of the Special Education Act
[10] was amended to first include the wording of Functional Behavioral Intervention into the law. The law requires the IEP to be developed by a professional team, including the following parts:

(a) The student's present status of abilities, family, and need assessment, (b) the student's needs in special education, related services, and support strategies, (c) the school's year/semester educational goals, assessment means, dates, and criteria of educational objectives per semester, (d) functional behavioral intervention and administrative support needed for students with emotional and behavioral problems, and (e) transitional counseling and services for students.

IDEA 2004 also recognizes the significance of professional development in facilitating the implementation of PBS. IDEA authorizes states to use professional development funds to provide training on PBS for pre-service and in-service special educators and further provide joint training to the entire school personnel in order to implement school-wide PBS. In Taiwan, although the law has not specifically mandated professional development funds to provide teacher training on PBS, due to practical needs of school personnel, most departments of education in Taiwan's cities or counties have organized several in-service teacher training programs to enhance special educators' competency in PBS.

The empirical literature describes a variety of teacher training programs or curricula aimed to enhance the knowledge of PBS, and the ability to write high-quality behavior intervention plans. Browning-Wright et al. [1] evaluated the effects of two training programs on increasing professional competencies in PBS and the quality of positive behavior support plans. Two hundred behavior specialists in California participated in that study. Training one consisted of six key concepts of applied behavior analysis (ABA), 
including behavior function, situational specificity, behavior change, reinforcement tactics, reactive strategies, and team coordination and communication. Training two focused on how to evaluate the quality of behavior intervention plans using an evidence-based rating instrument, Behavior Support Plan-Quality Evaluation (BSP-QE). Results showed the participants were more likely to develop good or superior PBS plans after receiving training on how to evaluate the quality of PBS plans, compared to receive training on six ABA concepts alone. It appeared that behavior specialists could be trained to learn how to evaluate and write good behavior plans. The researchers pointed out that it was important to include the components of BSP-QE in the training ingredients to better develop consistent PBS plans.

Although past research had shown that teacher training can be effective in developing high-quality PBS plans and implementation of behavior support skills, there is not yet a piece of research in Taiwan that systematically investigates whether teacher training has effects on the knowledge of PBS and the quality of behavior intervention plans. Most special educators in Taiwan never received extensive coursework in ABA or PBS during their pre-service and in-service training, nor did they receive enough training on writing good PBS plans, although the special education law requires the teachers to do so. The education authorities may intend to develop "crash course" training on Functional Behavior Assessment (FBA) and behavior intervention planning; however, such training may be not sufficient for school-based teams to apply evidence-based practices in schools (Scott et al. [9]). To be the first study in Taiwan that systematically investigates the effects of teacher training on the knowledge of PBS and the quality of PBS plans, the current study was designed to answer the following research questions: (a) After teacher training, can the participants grasp the key concepts of PBS? (b) After teacher training, can the participants develop behavior intervention plans of higher quality?

\section{Method}

\subsection{Participants}

Thirty-seven teachers from three public schools participated in the study. All three schools were located in the southern part of Taiwan. Two schools were special education schools, and the remaining one was an elementary school. School A was a special education school, from which 9 teachers participated in the study. These participants included 3 special education teachers, 5 school administrators (which were also special education teachers), and 1 related service professional (i.e., a school psychologist). School B was a special education school, from which 13 teachers participated in the study. The participants included 3 special education teachers, 8 school administrators (including a school principal, 7 administrators were also special education teachers), and 2 related service professional (i.e., a social worker and an occupational therapist). School $\mathrm{C}$ had 15 teachers participated in the study. They included 10 special education teachers, 2 general classroom teachers, 2 intern teachers, and 1 school psychologist. All participants were selected due to their urgent needs to deal with students' behavioral problems in classrooms. A certificate of training completion would be awarded to the participant who attended over $80 \%$ of training, in order to avoid experimental mortality.

The total of 36 teachers was divided into 7 groups, and each group was asked to work together and submit a behavior intervention plan for one student with problem behaviors. The size of each group ranged from 2-8 participants. Members of each group were from the same school, and the participants selected their own members. Group 1 and 2 were from School A; Group 3 and 4 were from School B, and the rest 3 groups were from School C. Consent forms were obtained from the participants prior to the study.

\subsection{Teacher Training}

All trainings were conducted by the experimenter, who has a doctoral degree in special education, and is also a Board Certified Behavior Analyst-Doctoral level. Training courses were held in the library of one participating special education school. There were 12 training sessions, and each lasted for three hours. The training sessions were provided from December, 2015 to April, 2016. The class met once a week or every two weeks.

The training adopted a competency-based approach, which involved verbal or knowledge training components of PBS (Reid et al. [7]). The content for the training sessions was based on previous research of positive behavior support planning. The key concepts covered throughout the training were adopted and adapted from Niu [6], Browning-Wright et al. [1] and Kincaid, George \& Childs [4]. The topics addressed during the entire training sessions are presented in Table 1. The topic of team coordination and communication skills (Browning-Wright et al. [1]; Kincaid et al. [4]) was not specifically included in the training, although some principles of coordination and communication were already embedded within some sessions. 
Table 1. The key Concepts Presented for Each Training Session and the Corresponding PBS Plan Components

\begin{tabular}{|c|c|c|c|}
\hline Session & Key Concept/Topic & Included Reason & $\begin{array}{l}\text { Corresponding PBS Plan } \\
\text { Components }\end{array}$ \\
\hline 1 & $\begin{array}{l}\text { Introduction: applied } \\
\text { behavior analysis and } \\
\text { positive behavior support }\end{array}$ & Brief introduction of $\mathrm{ABA}$ and $\mathrm{PBS}$ principles. & \\
\hline 2 & $\begin{array}{l}\text { Selecting and defining target } \\
\text { behaviors }\end{array}$ & $\begin{array}{l}\text { The PBS plan must objectively define the target behaviors } \\
\text { to be changed. }\end{array}$ & $\begin{array}{c}\text { Student Information } \\
\text { Selecting and defining target } \\
\text { behaviors } \\
\text { 5-1 Defining replacement behaviors }\end{array}$ \\
\hline 3 & $\begin{array}{l}\text { Data-based behavior } \\
\text { observation and recording }\end{array}$ & $\begin{array}{c}\text { The PBS plan must measure the target behavior to } \\
\text { determine whether the behavior change after the treatment } \\
\text { is implemented. }\end{array}$ & $\begin{array}{l}\text { Observing and recording target } \\
\text { behaviors }\end{array}$ \\
\hline 4 & $\begin{array}{l}\text { Implementing functional } \\
\text { behavior assessments }\end{array}$ & $\begin{array}{l}\text { The PBS plan must identify the function of the problem } \\
\text { behavior to develop functionally equivalent replacement } \\
\text { behavior. }\end{array}$ & $\begin{array}{l}\text { Implementing functional behavior } \\
\text { assessments }\end{array}$ \\
\hline 5 & Using antecedent strategies & $\begin{array}{c}\text { The PBS plan must specify function-based antecedent } \\
\text { strategies to evoke desirable behaviors or decrease } \\
\text { undesirable behaviors. }\end{array}$ & 5-2 Using antecedent strategies \\
\hline 6 & $\begin{array}{l}\text { Using motivation operation } \\
\text { and stimulus control }\end{array}$ & $\begin{array}{c}\text { Teach teachers to use motivation operation strategies to } \\
\text { increase or decrease motivation to demonstrate target } \\
\text { behaviors, and to establish stimulus control to evoke } \\
\text { desirable behaviors. }\end{array}$ & 5-2 Using antecedent strategies \\
\hline 7 & $\begin{array}{c}\text { Using ecological } \\
\text { environment management } \\
\text { strategies }\end{array}$ & $\begin{array}{l}\text { The PBS plan should identify strategies in students' } \\
\text { ecological environment to promote long-term behavior } \\
\text { change. }\end{array}$ & $\begin{array}{l}\text { 5-2 Using ecological environment } \\
\text { management strategies }\end{array}$ \\
\hline 8 & $\begin{array}{c}\text { Using behavior instruction } \\
\text { strategies }\end{array}$ & $\begin{array}{c}\text { The PBS plan should specify strategies to teach alternative } \\
\text { replacement behaviors. }\end{array}$ & $\begin{array}{l}\text { 5-2 Using behaviors instruction } \\
\text { strategies }\end{array}$ \\
\hline 9 & $\begin{array}{l}\text { Using reinforcement, } \\
\text { punishment and extinction }\end{array}$ & $\begin{array}{c}\text { The PBS plan should include reinforcement or punishment } \\
\text { strategies to increase desirable behaviors and decrease } \\
\text { undesirable behaviors. }\end{array}$ & $\begin{array}{l}\text { 5-2 Using reinforcement and } \\
\text { punishment strategies }\end{array}$ \\
\hline 10 & $\begin{array}{l}\text { Implementation of the } \\
\text { three-tiered prevention } \\
\text { approach }\end{array}$ & $\begin{array}{l}\text { Evidence-based strategies should be taught and applied } \\
\text { within each tier of the PBS system. }\end{array}$ & $\begin{array}{l}\text { 5-4 Embed three-tiered prevention } \\
\text { strategies into the school's present } \\
\text { three-tier prevention system } \\
\text { 5-5 Develop crisis plan }\end{array}$ \\
\hline 11 & $\begin{array}{l}\text { Using strategies to promote } \\
\text { behavior maintenance and } \\
\text { generalization }\end{array}$ & $\begin{array}{l}\text { The PBS plan should include strategies to systematically } \\
\text { program for maintenance and generalization of the } \\
\text { desirable behaviors. }\end{array}$ & $\begin{array}{l}\text { 5-2 Using strategies to promote } \\
\text { maintenance and generalization } \\
\text { 5-2 Other strategies } \\
\text { 5-3 Select viable strategies }\end{array}$ \\
\hline 12 & $\begin{array}{l}\text { Implementation and } \\
\text { evaluation of PBS plan }\end{array}$ & $\begin{array}{l}\text { Review quality indicators of PBS implementation and PBS } \\
\text { plans. Have the class discuss implementation difficulties } \\
\text { encountered so far. }\end{array}$ & $\begin{array}{l}\text { 5-6 Graphing intervention data } \\
\text { 6. Evaluation of PBS plan }\end{array}$ \\
\hline
\end{tabular}

During training sessions, the experimenter delivered PowerPoint presentations. The class notes were distributed at the beginning of each session. In addition to didactic presentations, case studies were provided for small group discussions. The participants also discussed effective strategies to be used in their own classrooms or for specific student's problem behaviors. Starting from Session 2, each group was required to complete a corresponding component of the PBS plan after class. For example, at the week of learning how to conduct functional behavior assessment, each group was required to complete the "functional behavior assessment" section in their PBS plan, and uploaded their homework to dropbox one day prior to the next class. The experimenter as an instructor would provide written feedback using Microsoft Word's "Track Change" function. At the beginning of the next class, the experimenter reviewed each group's work, verbally explained the written feedback, and allowed the class to ask questions. Then the group was allowed to make a revision of the assigned section. This process continued until each group completed an entire PBS plan. The PBS plan components and their corresponding training topics are presented in Table 1.

Each training session was videotaped to allow the participants who did not attend that session to make up for missed classes. For the participants who did not attend the session, they were required to watch the video, discuss the key concepts covered in that session with the group leader, and write a session reflection report. 
Table 2. The PBS Plan Component Checklist, the Corresponding PBS Component Used in This Study, and the Scoring Rubric for Each Component

\begin{tabular}{|c|c|}
\hline Components to Evaluate & Scoring Rubric \\
\hline $\begin{array}{l}\text { 1. Problem behaviors in observable and measurable terms } \\
\text { (Matches PBS plan 2. Selecting and Defining Target Behaviors) }\end{array}$ & $\begin{array}{c}\text { 2: Behavior(s) are observable and measurable } \\
\text { 1: Some of the behavior(s) are not observable and measurable } \\
0: \text { None of the above }\end{array}$ \\
\hline $\begin{array}{l}\text { 2. Predictors of behaviors, including: physical setting, social setting, } \\
\text { instructional factors, scheduling factors, degree of independence, } \\
\text { degree of participation, social interaction, and degree of choice } \\
\text { (Matches PBS plan 1. Student Information) }\end{array}$ & $\begin{array}{l}\text { 2: One or more environmental predictors are described with details } \\
\text { 1: One or more environmental predictors are given, but with no detail } \\
\qquad 0 \text { : None of the above }\end{array}$ \\
\hline $\begin{array}{l}\text { 3. Identified antecedent environmental variables influencing } \\
\text { behavior } \\
\text { (Matches PBS plan 4. Implementing Functional Behavior } \\
\text { Assessments) }\end{array}$ & $\begin{array}{l}\text { 2: Half or more of the environmental variables are logically related to } \\
\text { behavior } \\
\begin{array}{c}\text { 1: Less than half of the environmental behaviors are logically related } \\
\text { behavior } \\
0: \text { None of the above }\end{array}\end{array}$ \\
\hline $\begin{array}{l}\text { 4. Specified environmental, curriculum and/or interaction changes to } \\
\text { remove need to exhibit the problem behavior } \\
\text { (Matches PBS Plan 5-2\&5-3: Develop Function-based Intervention } \\
\text { Strategies; Select Viable Strategies) }\end{array}$ & $\begin{array}{l}\text { 2: One or more environmental changes are specified and are logically related } \\
\text { to behavior } \\
\begin{array}{c}\text { 1: One or more environmental variable changes are described but they are } \\
\text { not logically related to behavior } \\
0: \text { None of the above }\end{array}\end{array}$ \\
\hline $\begin{array}{l}\text { 5. Identified function of the behavior } \\
\text { (Matches PBS plan 4. Implementing Functional Behavior } \\
\text { Assessments) }\end{array}$ & $\begin{array}{l}\text { 2: All identified function(s) are identified, and are logically related to } \\
\text { behavior } \\
\text { 1: All identified function(s) are identified } \\
\text { but not all are logically related to behavior } \\
\text { 0: Function(s) are not specified }\end{array}$ \\
\hline $\begin{array}{l}\text { 6. Replacement behavior serve the same function as the problem } \\
\text { behavior } \\
\text { (Matches PBS plan 5-1: Defining Replacement Behaviors) }\end{array}$ & $\begin{array}{l}\text { 2: All specified functionally equivalent replacement behaviors(FERB) serve } \\
\text { the same function as the problem behavior } \\
\text { 0: No FERB is identified }\end{array}$ \\
\hline $\begin{array}{l}\text { 7. Teaching strategies adequately specify how to teach or prompts } \\
\text { FERB } \\
\text { (Matches PBS Plan 5-2\&5-3: Develop Function-based Intervention } \\
\text { Strategies; Select Viable Strategies) }\end{array}$ & $\begin{array}{c}\text { 2: Teaching strategies for all FERB }(\mathrm{s}) \text { are described in details } \\
\text { 1: Some teaching strategies with at least one detail are specified } \\
0: \text { No strategies are specified to teach a FERB }\end{array}$ \\
\hline $\begin{array}{l}\text { 8. Specified reinforcers the student is known to seek } \\
\text { (Matches PBS Plan 5-2: Develop Function-based Intervention } \\
\text { Strategies) }\end{array}$ & $\begin{array}{l}\text { 2: Reinforcer for FERB is complete and specified, preference or reinforcer } \\
\text { assessment is done } \\
\begin{array}{r}\text { 1: Reinforcer for FERB is identified without conducting preference or } \\
\text { reinforcer assessment } \\
\text { 0: No reinforcer is identified }\end{array}\end{array}$ \\
\hline $\begin{array}{c}\text { 9. Progress monitoring _ goals and objectives } \\
\text { (Matches PBS plan 5-6 \& 6: Graphing intervention data; evaluation } \\
\text { of PBS Plan) }\end{array}$ & $\begin{array}{l}\text { 2: The FERB goal contains } 6 \text { components, including - by when, who, will } \\
\text { do or not do what, under what conditions, at what level of proficiency, } \\
\text { measured how, and by whom } \\
\text { 1: The FERB goal contains } 3-5 \text { components } \\
\text { 0: The FERB goals contains } 1-2 \text { components }\end{array}$ \\
\hline $\begin{array}{l}\text { 10. The plan identifies all personnel to implement, monitor and } \\
\text { exchange information } \\
\text { (Matches PBS plan 6: Evaluation of PBS plan) }\end{array}$ & $\begin{array}{c}\text { 2: All implementers are identified and their responsibilities are specified } \\
\text { 1: Not all implementers are identified or not all responsibilities are specified } \\
0: \text { No member responsibilities are identified }\end{array}$ \\
\hline $\begin{array}{l}\text { 11. Functional assessments were conducted, including questionnaire } \\
\text { and direct observation. } \\
\text { (Matches PBS plan 4. Implementing Functional Behavior } \\
\text { Assessments) }\end{array}$ & $\begin{array}{l}\text { 2: Functional assessments were conducted using multiple measures } \\
\text { 1: Functional assessment was conducted using direct observation only or } \\
\text { questionnaire only. } \\
0 \text { : No functional assessment was conducted }\end{array}$ \\
\hline $\begin{array}{c}\text { 12. Generalization and maintenance strategies are specified } \\
\text { (Matches PBS Plan 5-2\&5-3: Develop Function-based Intervention } \\
\text { Strategies; Select Viable Strategies) }\end{array}$ & $\begin{array}{l}\text { 2: Various generalization and maintenance strategies were used } \\
\text { 1: Some generalization and maintenance strategies were used } \\
0: \text { None of the above }\end{array}$ \\
\hline $\begin{array}{l}\text { 13. Review schedule of behavior plan was specified } \\
\text { (Matches PBS plan 6: Evaluation of PBS plan) }\end{array}$ & $\begin{array}{l}\text { 2: Review schedule of behavior plan was specified } \\
0: \text { None of the above }\end{array}$ \\
\hline $\begin{array}{c}\text { 14. Data recording } \\
\text { (Matches PBS plan 3. Observing and Recording Target Behaviors) }\end{array}$ & $\begin{array}{c}\text { 2: baseline and intervention data were graphed } \\
\text { 1: Baseline and intervention data were not adequately graphed } \\
0: \text { None of the above }\end{array}$ \\
\hline $\begin{array}{l}\text { 15. Embed three-tiered prevention strategies into the school's } \\
\text { present three-tier prevention system/ Develop crisis plan } \\
\text { (Matches PBS plan 5-4 \& 5-5: Embed three-tiered prevention } \\
\text { strategies into the school's present three-tier prevention system; } \\
\text { develop crisis plan) }\end{array}$ & $\begin{array}{l}\text { 2: Embed three-tiered prevention strategies into the school's present } \\
\text { three-tier prevention system or develop crisis plan } \\
\text { 1: Develop three-tiered prevention strategies but not embed within the } \\
\text { school's present prevention system } \\
\text { 0: None of the above }\end{array}$ \\
\hline
\end{tabular}




\subsection{Dependent Variables}

There were three dependent variables. The first one was the percentage of correct competency-based responses using pre-test post-test comparisons. This dependent variable was used to measure the participants' knowledge gains on PBS. Starting from Session 2, prior to each session, pre-tests were distributed and the participants were given 15-20 minutes to complete the tests. Each test included 10 multiple-choice questions related to the content for that training session, except there was one test using 4 short-answer questions. Multiple-choice questions were selected as test questions because they were less time-consuming, and they required less effort to complete. At the end of each session, the same tests were used as post-tests, and the participants were allowed to check their answers again and make a revision as needed. The tests were then collected and graded by the experimenter. The percentage correct answers were calculated. The experimenter had pre-determined that the mastery criterion for each test was $70 \%$ accuracy.

The second dependent variable was the number of components in PBS plans before and after the training. The PBS plan component checklist was adapted from The Behavior Intervention Plan-Quality Evaluation Guide (BIP-QE) (Browning-Wright, Meyer, \& Saren [2]) and Williams and Vollmer [11] (See Table 2). Some components in BIP-QE were not included in the checklist, such as the team communication during the implementation, treatment integrity and reliability checks. This was because team communication was not included in the training sessions. In addition, for educational practitioners, treatment integrity and reliability may not be practical to be measured in natural settings. There were a total of 15 components on the PBS plan component checklist. The components of PBS plans used in each school prior to the study were compared to the PBS plan used after the study.

The third dependent variable was the quality of PBS plans before and after performance feedback was given. Data were collected and analyzed by groups. Each group was required to complete a corresponding component of PBS plans after class. The experimenter then provided written feedback to each group's work. The quality of each PBS plan component was compared prior to and after the written feedback was given. The scoring rubric for each component ranged from $0-2$. Each score category described the characteristics of responses that would receive the respective score. The detailed description of the scoring rubrics is shown in Table 2.

\subsection{Experimental Design and Data Collection}

The study used a group pretest-training-posttest pre-experimental design. The independent variable was teacher training. The dependent variables were: the percentage of correct competency-based responses, the number of components in PBS plans, and the quality of PBS plans. To measure the percentage of correct competency-based responses, pre-tests were administered prior to each training session and post-tests were administered at the end of each training session. To measure the number of components in PBS plans, pretest data were collected prior to the study, and posttest data were collected after the study. To measure the quality of PBS plans, pretest data were collected prior to the written feedback was given, and posttest data were collected after the feedback was given and the group made a revision to the plan.

\subsection{Interscorer Agreement and Procedural Integrity}

The pre-tests and post-tests were collected and independently scored by the experimenter and another scorer. The independent scorer was a graduate student in special education. Prior to the study, the independent scorer was trained by the experimenter, who explained to the scorer the scoring system of the tests and PBS plans. In addition, during training the experimenter provided correct, partially correct and incorrect examples of each item in PBS scoring rubrics for practice. The independent scorer practiced scoring tests and rated PBS plans until reaching at least $80 \%$ accuracy with the experimenter for two consecutive sessions. The interscorer agreement (ISA) was calculated by dividing the number of agreements by the number of agreements plus disagreements, and then multiplying by 100 . ISA data were collected for all pre-tests, post-tests, and PBS plan ratings. ISA was calculated to be $92 \%$ (ranged from $70 \%$ to $100 \%$ ) for pre-tests and post-tests, and $88 \%$ (ranged from $65 \%$ to $100 \%$ ) for PBS plan ratings. Procedural integrity check was not collected by an independent observer. However, the experimenter made a self-checklist of instructional activities for each session, and self-monitored the integrity of the training procedure.

\subsection{Social Validity}

The social validity survey was conducted at the end of the last training session. There were $69 \%$ of the participants who completed the survey. There were $89 \%$ of the participants who recognized the training goals as "important" and "very important". There were $86 \%$ of the participants who rated the training procedure as "good" and "very good". In terms of the acceptability of training outcomes, the results varied according to different items. Overall, $93 \%$ of the participants were satisfied and very satisfied with the training outcomes.

\section{Results}

\subsection{The Percentage of Correct Competency-based Responses}

The percentage of correct competency-based responses in pre-tests and post-tests is shown in Figure 1. The average score for all training topics increased from pre-tests to 
post-tests, ranging from 0.5 to 3.5 points. For the training topic "Ecological Strategies" and "Three-Tier Prevention Strategies", the average score increased the least from pre-tests to post-tests. For the training topic "Motivating Operation (MO)", the average score increased the most from pre-tests to post-tests. Among the 10 training topics, 8 post-tests reached the $70 \%$ mastery criterion. The topics which did not meet the mastery criterion during post-tests were: "Defining Behaviors", and "Maintenance and Generalization".

The results of correlated group t-tests and effect size are shown in Table 3. Among the 10 training topics, 8 of them presented significant differences between pre-tests and post-tests. There was no significant difference in the mean of pre-tests and post-tests on "Ecological Strategies" and "Three-Tier Prevention Strategies".

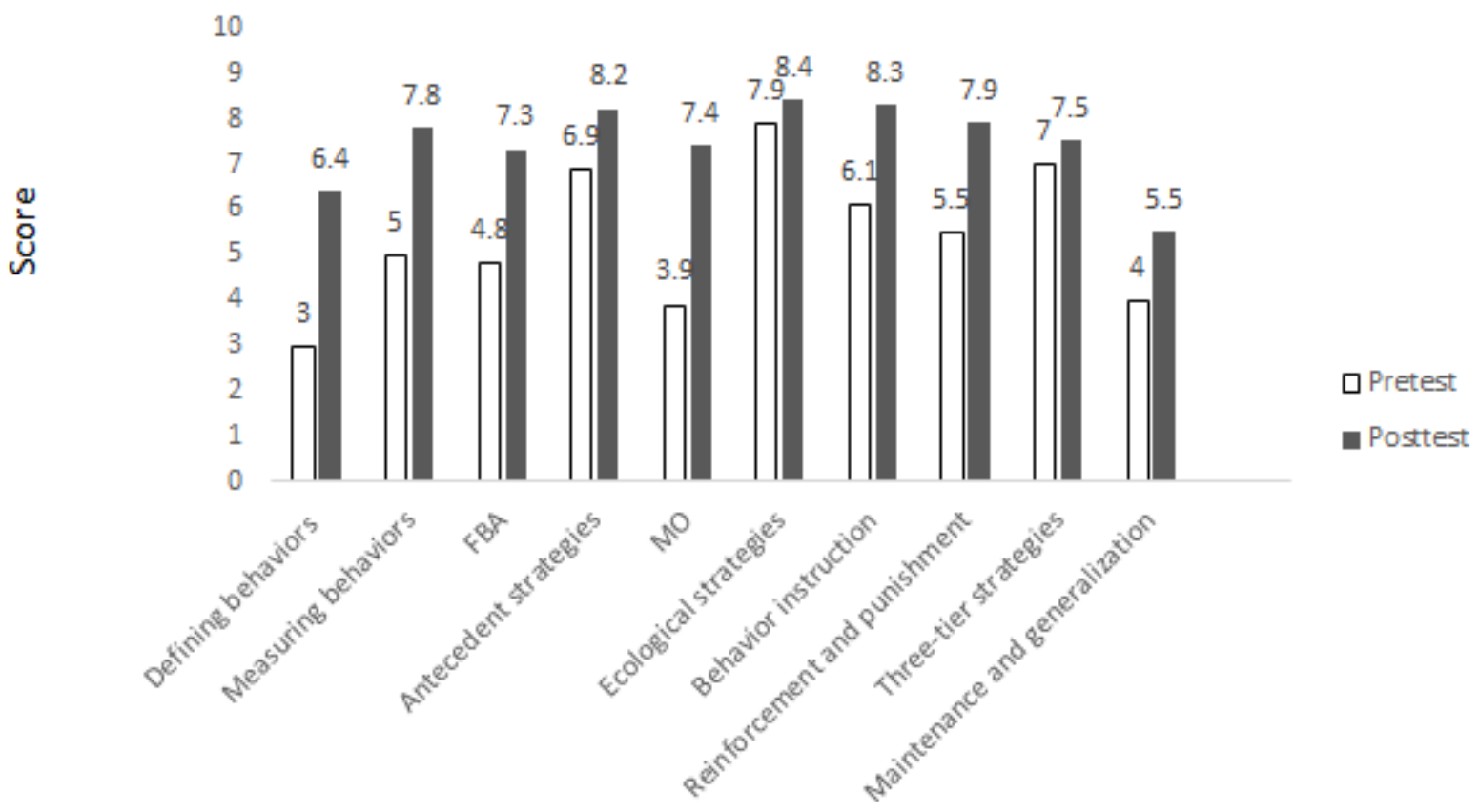

Figure 1. Pre- and Post-test Results for the Percentage of Correct Competency-based Responses

Table 3. Changes in the Means of Pre-tests and Post-tests: Results of Correlated Group T-Tests and Effect Size

\begin{tabular}{|c|c|c|c|c|c|c|c|c|c|}
\hline \multirow{2}{*}{ Variables } & \multicolumn{2}{|c|}{ Pre-test } & \multicolumn{2}{|c|}{ Post-test } & \multirow{2}{*}{$\mathrm{t}$} & \multirow{2}{*}{$\mathrm{p}$} & \multicolumn{2}{|c|}{$95 \% \mathrm{CI}$} & \multirow{2}{*}{ Cohen D } \\
\hline & M & SD & M & SD & & & LL & UL & \\
\hline Defining behaviors & 3.03 & 1.35 & 6.41 & 1.37 & $9.67 * * *$ & .000 & 2.63 & 4.12 & 2.49 \\
\hline Measuring behaviors & 5.00 & 2.03 & 7.82 & 1.19 & $6.69 * * *$ & .000 & 1.93 & 3.72 & 1.69 \\
\hline FBA & 4.80 & 2.63 & 7.30 & 1.67 & $4.16^{* *}$ & .001 & 1.24 & 3.76 & 1.13 \\
\hline Antecedent strategies & 6.90 & 1.92 & 8.20 & 1.15 & $4.47 * * *$ & .000 & .69 & 1.91 & 0.82 \\
\hline $\mathrm{M}$ & 3.95 & 1.88 & 7.40 & 1.76 & $7.13 * * *$ & .000 & 2.44 & 4.46 & 1.89 \\
\hline Ecological strategies & 7.91 & 1.18 & 8.38 & 1.02 & 2.02 & .056 & -.01 & .97 & 0.43 \\
\hline Behavior instruction & 6.17 & 1.85 & 8.25 & 1.14 & $3.23 * *$ & .008 & .66 & 3.50 & 1.35 \\
\hline $\begin{array}{c}\text { Reinforcement and } \\
\text { punishment }\end{array}$ & 5.56 & 1.98 & 7.94 & 1.86 & $4.99 * * *$ & .000 & 1.38 & 3.40 & 1.24 \\
\hline Three-tier strategies & 7.00 & 1.63 & 7.50 & 2.17 & 1.46 & .177 & -.27 & 1.27 & 0.26 \\
\hline $\begin{array}{l}\text { Maintenance and } \\
\text { generalization }\end{array}$ & 4.08 & 1.71 & 5.54 & 1.45 & $3.27 * *$ & .007 & .49 & 2.44 & 0.92 \\
\hline
\end{tabular}

$* * \mathrm{p}<.01 * * * \mathrm{p}<.001$ 


\subsection{The Number of Components in PBS Plans}

The number of components in PBS plans was compared prior to and after the study. Data were analyzed by schools. The PBS plan component checklist in Table 2 was used to evaluate the required components of PBS plans. There were a total of 15 required components in the checklist. As shown in Figure 2, prior to the study, School A's positive behavior support plan only had one essential component-Progress Monitoring. After the study, School A adopted the PBS plan form used during training, and therefore the plan contained all 15 components in the checklist. School B's PBS plan had 4 essential components prior to the study. After the study, School B revised its PBS plan form to include key components covered in the training sessions. The revised plan contained 14 components in the checklist, except the inclusion of maintenance and generalization strategies. School C used the same PBS plan form as School A. After the study, School $\mathrm{C}$ also adopted the form used during training.

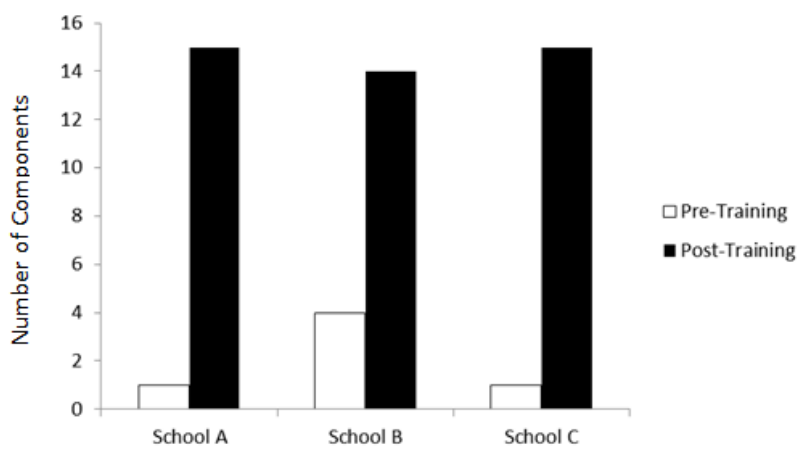

Figure 2. The Number of Components in PBS Plans Based on the Component Checklist
A chi-square test of independence was performed to further examine the number of components in the PBS plans prior to and after the teacher training. As shown in Table 4, the change in PBS components was significant (chi-square value $32.029, \mathrm{p}=.000<.05$ ). There was a significant change in the number of required components in PBS plans prior to and after the teacher training. The most significant change was that there were 34 number of PBS components appeared after the training.

Table 4. Results of the Chi-square Tests on the Number of Components in the PBS Plans Prior to and After the Training

\begin{tabular}{|c|c|c|}
\hline \multirow{2}{*}{ Pre-training } & \multicolumn{2}{|c|}{ Post-training } \\
\cline { 2 - 3 } & $\begin{array}{c}\text { The Number of } \\
\text { Components in the } \\
\text { PBS Plan }\end{array}$ & $\begin{array}{c}\text { The Number of } \\
\text { Components not in } \\
\text { the PBS Plan }\end{array}$ \\
\hline $\begin{array}{c}\text { The Number of } \\
\text { Components in the } \\
\text { PBS Plan }\end{array}$ & 6 & 0 \\
\hline $\begin{array}{c}\text { The Number of } \\
\text { Components not in } \\
\text { the PBS Plan }\end{array}$ & 34 & 1 \\
\hline
\end{tabular}

\subsection{The Quality of PBS Plans}

The quality of each PBS plan component was compared prior to and after the written feedback was given. The scoring rubric for each component was depicted in Table 2. Data were classified and analyzed by groups, as shown in Figure 3, 4 and 5. Overall, the quality of most components improved after training across all groups. Most groups did not reach satisfactory ratings on Component 8, 13,14 and 15. 


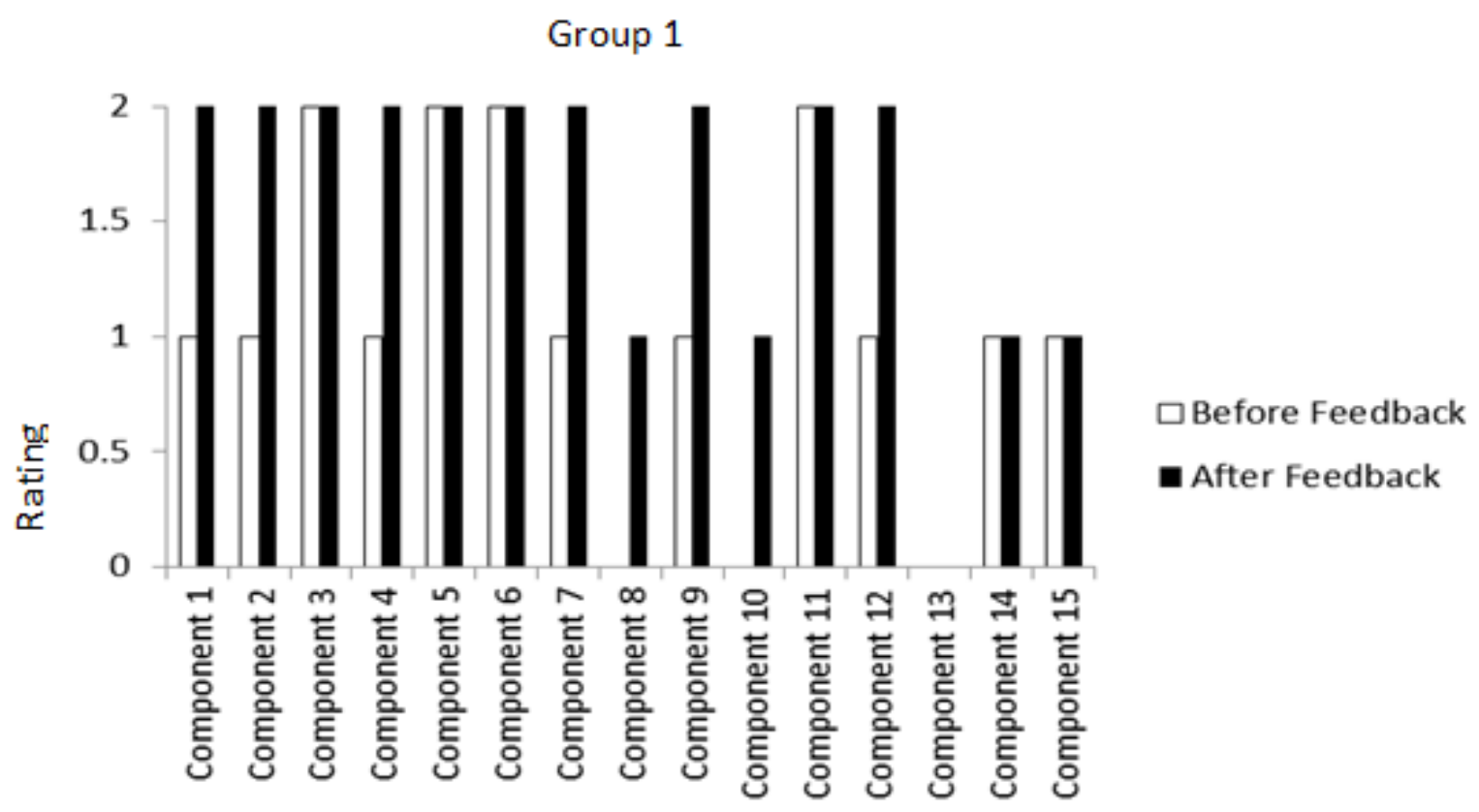

Group 2

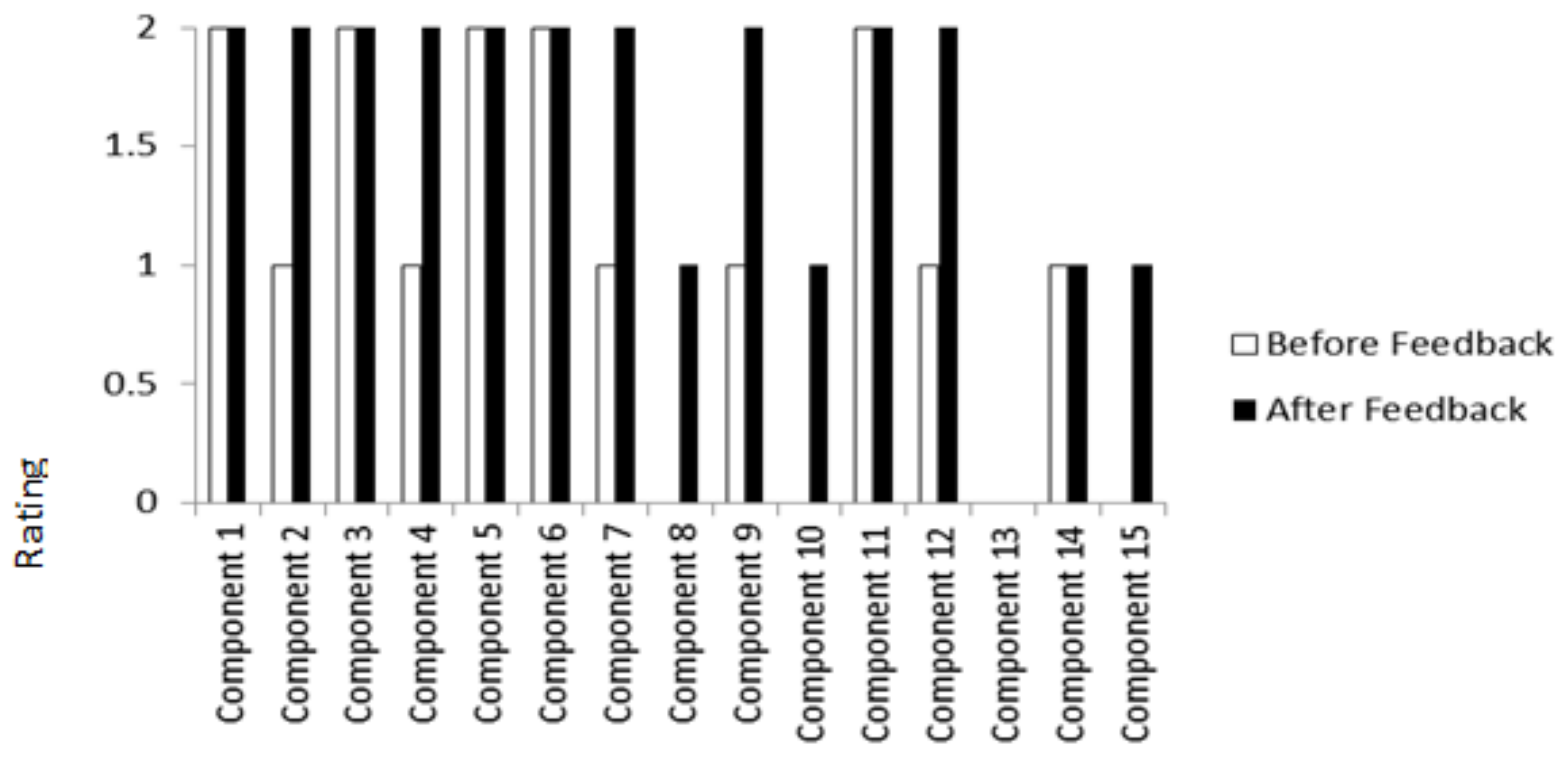

Figure 3. Comparison of PBS Plan Quality before and after Feedback for Group 1 and 2 (School A) 
Group 3
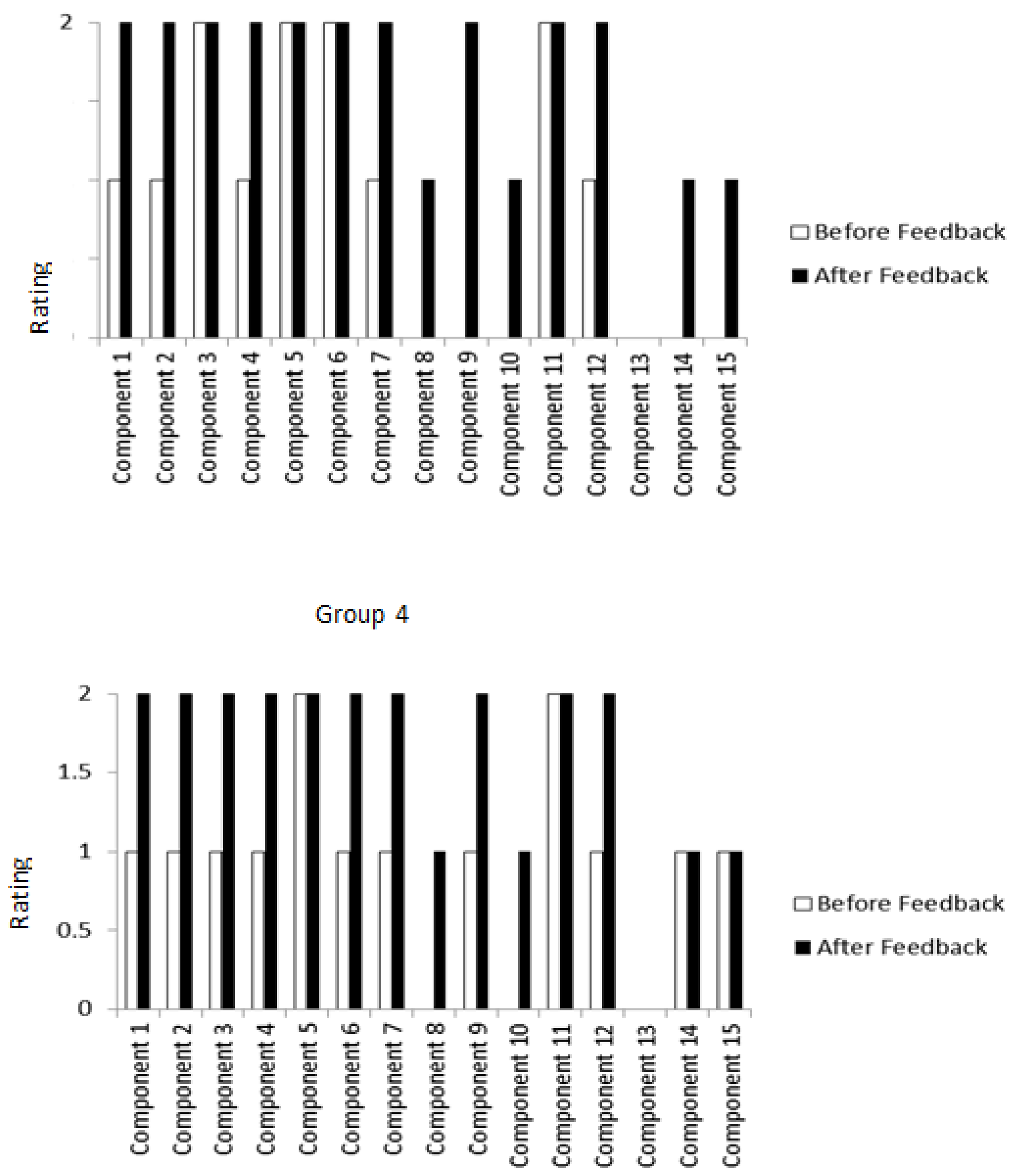

Figure 4. Comparison of PBS Plan Quality before and after Feedback for Group 3 and 4 (School B) 


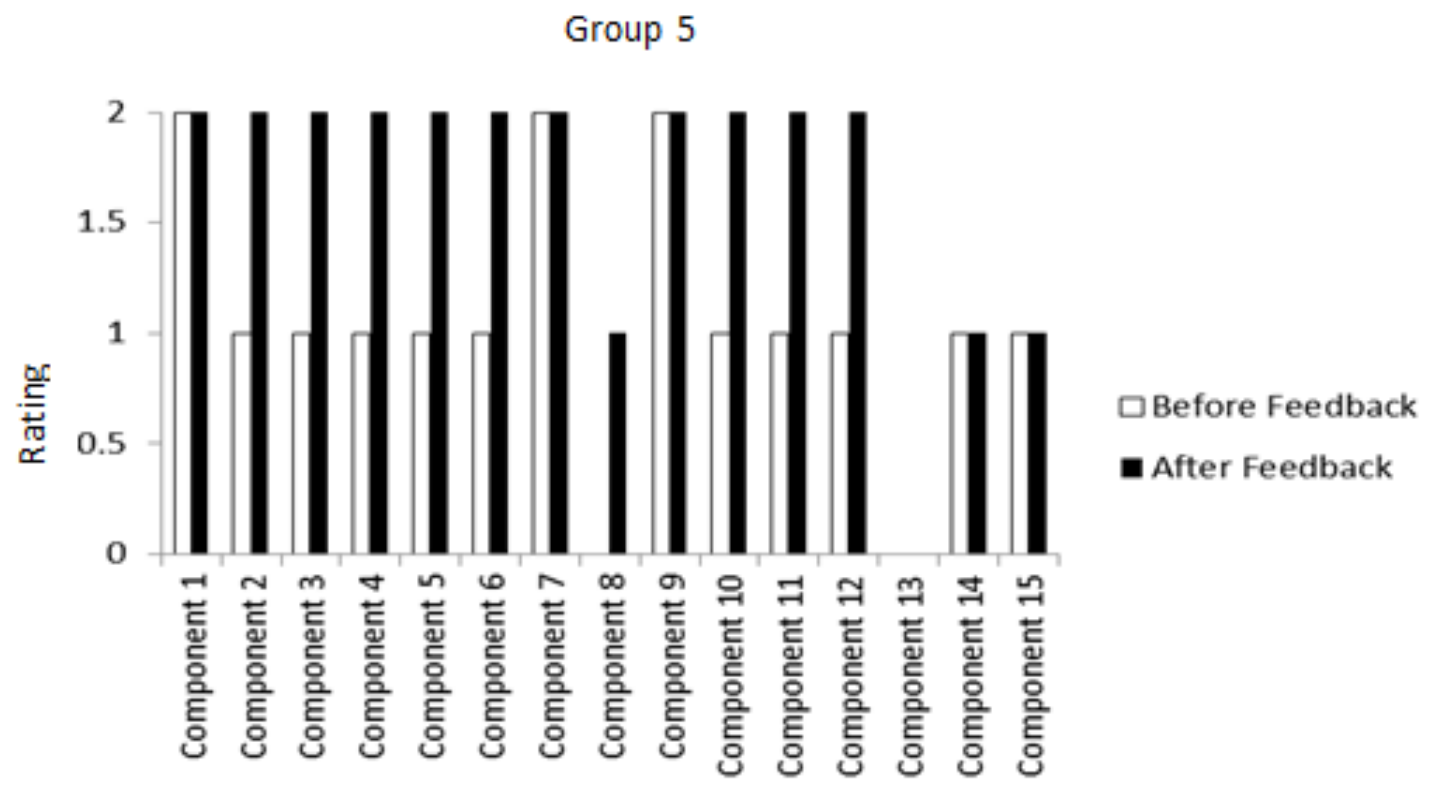

\section{Group 6}

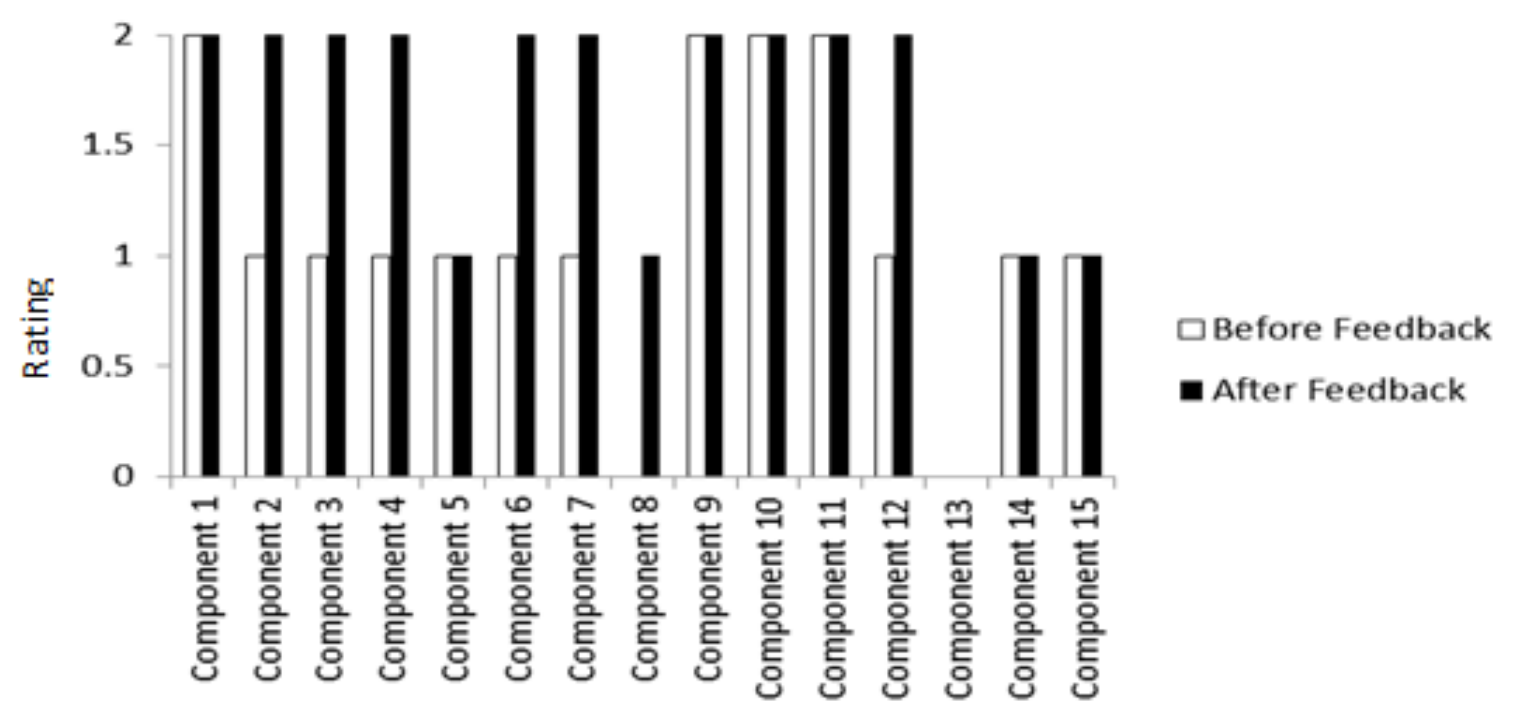


Group 7

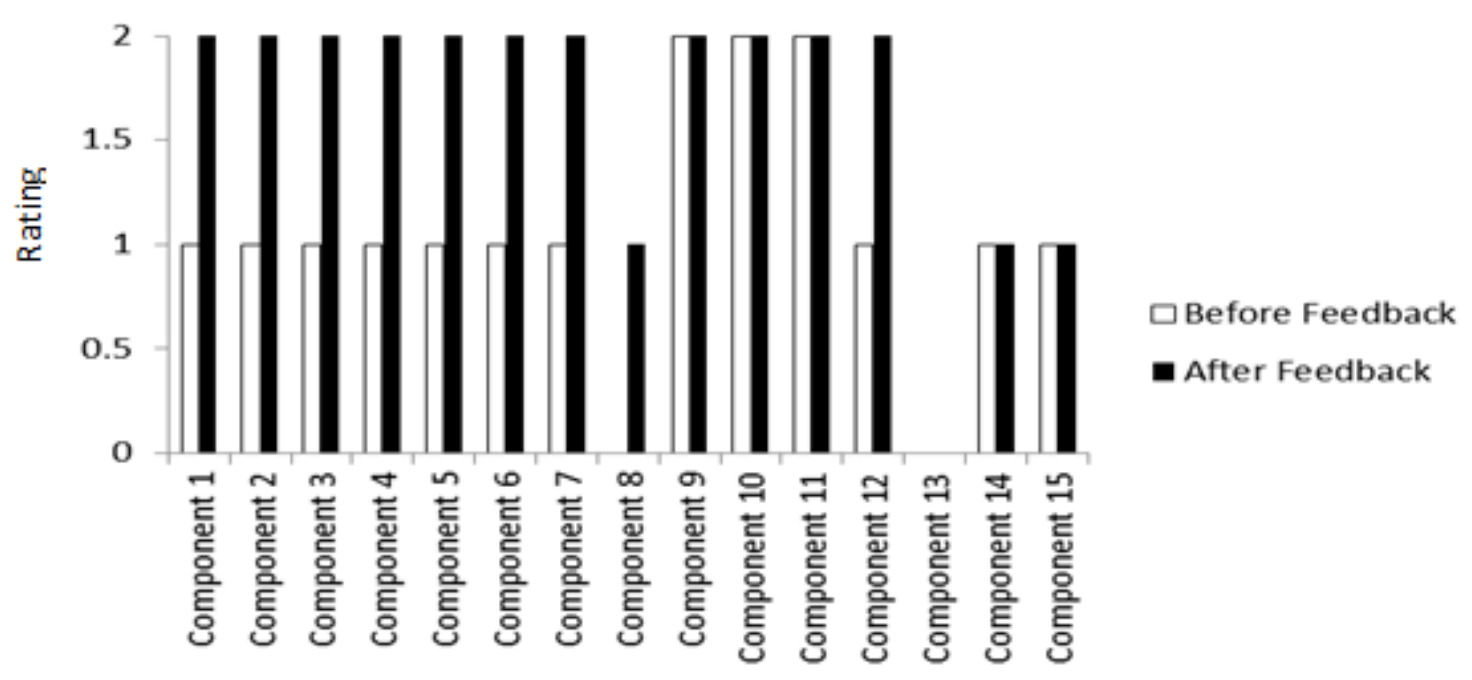

Figure 5. Comparison of PBS Plan Quality before and after Feedback for Group 5, 6 and 7 (School C)

\subsection{Discussion}

The current study indicated that the knowledge base of PBS and the substantive quality of PBS plans can be improved by providing teacher training. This result was consistent with the findings reported by other researchers (Browning-Wright et al. [1]; McClean \& Gray [5] ; Fabiano et al., 2013), who found that the teachers can be trained to learn more knowledge about PBS and write PBS plans of higher quality. Browning-Wright et al. [1] suggested training on writing PBS plans should align the key concepts of PBS with the components of PBS plans. This study developed a PBS plan component checklist, which was in alignment with the components of PBS plan forms used during the training. In addition, the scoring rubric of each component was used to evaluate the quality of the written plan. Although good behavior plans may not be sufficient to effectively decrease problem behaviors, it is a critical start point.

Although results showed teachers' knowledge on PBS improved after training, the extent of improvement was not quite significant for some training sessions. For example, the teachers' performance on "Antecedent Strategies", "Ecological Strategies", and "Three-tier Prevention Strategies" was already high in pretests, so the improvement after training was not significant. It was possible that most of the participating teachers were special education teachers, and these topics had already been taught in their pre-service or in-service teacher training. The participants' performance improved more in some sessions, such as "Defining Behaviors", "Measuring Behaviors", and "Motivating Operations (MO)". This may be because the key concepts covered in those three topics were more difficult or new to the participants. It was possible that these topics were more ABA-oriented, and therefore not familiar to most teachers.
More teacher training sessions could be dedicated to these topics in the future.

Multiple-choice questions were selected as the question format used in pre-tests and post-tests due to its low response-effort and it was less time-consuming. The test question format in Session 2 was short-answer questions. However, the experimenter noticed some participants did not complete their tests. Even for those participants who handed in their tests, a lot of them did not write much on the answer sheets. Therefore, the experimenter decided to use multiple-choice questions since Session 3. However, multiple-choice questions may not be able to appropriately assess the participants' real performance, which threatens the internal validity to determine whether the training actually improves teachers' knowledge on PBS.

It appeared that training on the quality indicators of PBS plans may result in higher quality in PBS plans. The training topics for this study included the key concepts of PBS, and these key concepts aligned with the required components in PBS plans, as shown in Table 1. Although each group had slight differences, the quality of most components was improved. The quality ratings of some components were not improved for most groups. For instance, Component 8 requires alternative behaviors be specified, be delivered contingently, show effectiveness, and be provided immediately and in variety. Reinforcement strategies were taught in Session 9. The experimenter explained basic principles of reinforcement, and used examples and case studies to illustrate how to apply reinforcement strategies. However, the training did not contain how to conduct preference assessment and reinforcer assessment, or how to use a schedule of reinforcement. Therefore, all groups were not able to reach the rating of " 2 ". In addition, all groups did 
not reach the satisfactory rating on Component 10, 13 and 14, either. These three components were related to the evaluation of PBS plans. Evaluating PBS plans was the last session of training, and therefore all groups were not be able to complete these three components on their PBS plans and receive the experimenter's feedback. In terms of Component 15, after 3-hour training on the three-tiered prevention strategies to be used within the school system, the participants reflected it was difficult to carefully examine the three-tiered strategies because this required the entire school to discuss and coordinate in order to build a school-wide behavior support system.

Moreover, during the study, in addition to case studies in class, each group was required to develop a PBS plan for one actual student with problem behaviors within the context of IEP. The training was somewhat generalizable to real-world situations. Some groups did implement the plan and were able to evaluate the effectiveness of the intervention. For example, three groups in School $\mathrm{C}$ implemented the plan during training, and they pointed out that the function-based interventions developed in the plan were effective. By the end of training, students' problem behaviors were already decreased to an acceptable level. Some other groups developed the plan, but did not implement the plan. Therefore, it was hard to determine whether the training was effective to have the participants generalize the written plan to practice.

There are some limitations in this study. First and foremost, a more rigorous experimental design should be used to extend research in this area. The current study used a pretest-posttest pre-experimental design with no control group at all. The poor validity of this design makes it difficult to demonstrate functional relationship for this study. The difference in the pre-test and post-test scores may be due to the participants' history events. In addition, pre-tests may sensitize the participants in unanticipated ways and therefore their performance may change due to the pre-tests, not the treatment. Furthermore, the participants' background information was not collected and analyzed, which may confound the study results. Although this study did control for some threats of internal validity, such as maturation and instrumentation, the study design lacks robust internal validity. The nature of the pretest-post pre-experimental design also failed to exclude the Hawthorne effect. Due to practicality concerns, it was not able to assign a control group because the teacher training in this study was publically funded. Despite the lack of "statistically" valid results, this study still has its "practicality" significance, because this is the first preliminary study in Taiwan that systematically investigates the effects of teacher training on the knowledge of PBS and the quality of PBS plans.

Second, the training provided in this study only involved competency-based training, without performance-based (Reid et al. [7]) or behavioral skills training (Sarokoff \& Sturmey [8]). The experimenter did not demonstrate the plan procedures and have the participants practice the skills in class. The training also did not involve observation of the teachers implementing the plan in natural contexts. Also, the study did not concomitantly assessed behavioral changes of students. Future research should examine whether the teachers are capable of implementing the plan with integrity, and make desirable changes on students' behaviors.

Third, the current study did not investigate whether the participants' demographic variables would impact the effectiveness of training. It is possible that some teachers may be more likely to benefit from training than other teachers may. Future research should examine the impact of different demographic characteristics on the effects of teacher training, such as age, level of education, number of years in teaching, or previous training on ABA or PBS (Browning-Wright et al., [1]).

Fourth, for the participants who did not attend the session, they were required to watch the video, discuss the key concepts covered in that session with the group leader, and write a session reflection report. This procedure allowed the participants to make up for missed sessions, because the training sessions were held on Friday afternoons, which were school working hours. However, the experimenter could not guarantee that the group leader did implement the predetermined session make-up procedure (i.e., watch the video together and discuss the key concepts, and give feedback to their session reflection reports). In addition, the experimenter did not collect data on how many participants watched videotapes for each session.

The final limitation pertains to the question format used for the pre and post-tests. Multiple choice questions may not be able to adequately assess the participants' mastery of key concepts. Other question formats could be considered, such as short answer questions or fill-in-blank questions. In addition, no test difficulty or discrimination analysis was done when creating the tests. This limitation may cause inconsistency of difficulty across the tests, thus affecting study results. Furthermore, in the current study, no contingency was established for not completing the tests, or answered poorly on the tests. The experimenter noticed that because the post-tests were distributed at the end of each session, some teachers would like to leave on time without handing in the tests, or they did not pay much attention or effort to complete the post-tests. Future training should exert class contingencies to prevent such possibilities. For example, the participants should earn a passing grade for each post-test in order to get a training certificate or proceed to the next training session.

In summary, this preliminary study demonstrated that teacher training enhanced teachers' knowledge on PBS and the quality of PBS plans, although the study results should be explained with caution due to its pre-experimental design. Future research may extend this study to investigate the best practices of teacher training programs on PBS. 


\section{REFERENCES}

[1] Browning-Wright, D.B., Mayer, G.R., Cook, C.R., Crews, S.D., Kraemer, B.R., \& Gale, B. (2007). A preliminary study on the effects of training using Behavior Support Plan Quality Evaluation Guide (BSP-QE) to improve positive behavioral support plans. Education and Treatment of Children, 30, 89-106.

[2] Browning-Wright, D., Mayer, G. R., \& Saren, D. (2013). Behavior Intervention Plan Quality Evaluation Scoring Guide (BIP-QE)II: To evaluate behavior intervention plans. Retrieved from http:// www.pent.ca.gov

[3] Individuals with Disabilities Education Improvement Act (2004).

[4] Kincaid, D., George, H.P., \& Childs, K. (2006). Review of the positive behavior support training curriculum: supervisory and direct support editions. Journal of Positive Behavior Interventions, 8, 183-188.

[5] McClean, B., \& Grey, I. (2012). A component analysis of positive behavior support plans. Journal of Intellectual and Developmental Disability, 37, 221-231. doi:10.3109/13668250.2012.704981.
[6] Niu, W. I. (2009). Positive behavior support for individuals with disabilities. Taipei: Psychological Publishing Co. Ltd. [Text in Chinese]

[7] Reid, D.H., Rotholz, D. A., Parsons, M. B., Morris, L., Braswell, B. A., Green, C. W., (2003). Training human service supervisors in aspects of PBS: Evaluation of a statewide, performance-based program. Journal of Positive Behavior Interventions, 5, 35-46.

[8] Sarokoff, R. A.,\& Sturmey, P. (2004). The effects of behavioral skills training on staff implementation of discrete-trial teaching. Journal of Applied Behavior Analysis, $37,535-538$.

[9] Scott, T. M., McIntyre, J., Liaupsin, C., Nelson, C. M., Conroy, M., \& Payne, L. D. (2005). An examination of the relation between functional behavior assessment and selected intervention strategies with school-based teams. Journal of Positive Behavior Interventions, 7, 205-215.

[10] The Enforcement Rules of the Special Education Act of Taiwan (2012, July 12).

[11] Williams, D.E., \& Vollmer, T.R. (2014). Essential components of written behavior treatment plans. Research in Developmental Disabilities, 36, 323-327. 